\title{
Argumentation IN ENGINEERING EDUCATION
}

\author{
Adriano J. Garcia and Tarso B. Mazzotti \\ Universidade Estácio de Sá - Rio de Janeiro - Brazil \\ adriano8080@gmail.com, tmazzotti@gmail.com
}

\begin{abstract}
Many engineering courses are disproportionately focused on the rigorous reasoning inherent in math, while professional practice requires further skills and competencies. Improving the effectiveness of teaching-learning processes in engineering requires a change in the instructional approach, a switch from exposition to argumentation. Research about the application of argumentation in the instruction of mathematics, science and related disciplines indicates that the articulation of reasons and theories through argumentative interventions stimulates the development of the reasoning agility that is required to justify, explain, respond and eliminate contradictions. By connecting these results to engineering education we conclude that an educational process based in argumentation potentially provides the opportunity for students to build much needed professional competencies because it enables critical thinking, empowers decision making among multiple possible solutions, and provides opportunities of presenting plausible justifications for chosen solutions.
\end{abstract}

Keywords: Engineering education, argumentation, critical thinking, professional competencies

\section{INTRODUCTION}

The engineering profession has an important role in activities that promote economic development and the construction of a civilized society. Newspaper articles, reports of international organizations, scientific research from different countries, and daily conversations point to the role of engineers in building the social good. However, many academic and business analyses, which implicitly or explicitly are based on the assumption of the centrality of engineering in a developed society, indicate that new engineers do not have the skill set required for professional practice.

As Ramadi et al. (2016) [1] point out, business representatives perceive gaps between their expectations about the skill set required for a good performance at work and what new engineers actually offer. Difficulty in managing time, an aspect that is key in any project and in the routine activities of the corporative world, and flawed communication, which constrains effectiveness in reaching strategic goals and inhibits the integration of teams, are the main gaps noted in the qualification of recently graduated engineers.

Reinforcing this perception, the Industry Strategic Map 2013-2022, prepared by the National Confederation of Industry - Brazil (CNI) [2], also shows that engineering professionals need better training in order to consistently achieve good performance. Such document points general education and training in engineering as major factors that need to be improved to support the growth of the Brazilian economy.

One of the main determinants of industrial competitiveness is labor productivity. Educated teams and well-trained engineers adequately utilize equipment, create better solutions to the problems of everyday life, optimize processes and products, and develop and implement innovations. In Brazil, poor basic education, reduced opportunities for technical education, and shortcomings in higher education limit the ability of companies to become innovative and productive. (CNI, 2013) [2].

Engineering is cited specifically as a field responsible for creating solutions to improve the competitiveness of companies and, indirectly, emerges as one of the main areas with a shortage of potential professionals who can properly perform in the ways and levels expected by companies. Many engineer positions remain vacant in companies because the skill set developed in engineering graduates does not match the skills required by companies.

Here we could discuss the supposed duality between training for life or for the market, which many educational institutions claim to focus on. However, pragmatically, we assume that those seeking an undergraduate degree hope to have job opportunities in their field, so the perception of companies is also relevant to students.

We could also revisit a discussion of how the engineering school is responsible for providing a technical foundation and not for the natural complementary skills that come with professional experience. However, we believe that while still incomplete at the end of graduation, the transition process between "student" and "professional" starts during undergraduate engineering education, and, it is expected that graduates will have the minimum skills to begin their professional practice.

Difficulty in landing a job in their field or having to accept positions not related to their education because 
they do not succeed in hiring processes for engineering positions, also cause frustration in recently graduated engineers.

Martin et al. (2005) [3] reports that newly graduated engineers believe that their education should have offered more opportunities to develop competencies for work in teams, to promote interpersonal relationships, and to learn techniques for effective communication.

It seems that both companies and new engineers believe that engineering programs are not being effective in training professionals. But what are the reasons for these shortcomings?

According to Crawley et al. (2010) [4], it is clear that universities aim to train successful engineers, but perhaps the dynamics of the educational process is not leading to such results. Engineering education has to manage the constant conflict between two incompatible necessities, the ambiguity of "being an expert" at the same time as having a "general and broad vision". Engineers need to master their field, which keeps continuously expanding thanks to new theories and new technologies that arise daily, and also need to know how to deal with different business areas, different types of companies, creating solutions to problems of all kinds, recognizing the ways that their surroundings affect their projects.

It would be naive trying to capture and instruct the entire body of knowledge of any field of engineering, therefore it may be important to identify which are the key concepts of each area and what is the essence of engineering. Reflecting on that, the following question is raised: what is the character of the engineer?

Picon (2004) [5] made a historical survey of engineering and the consolidation of "engineer" as a profession, finding that the central feature of engineering is the rationality applied to solve practical problems. It is important to note that this is a specific type of rationality, far from philosophical reasoning, which always maintains a practical goal in achieving the best solution to a societal problem.

If it is essential for engineers to be rational in order to create and implement practical solutions, the goal of the training process should be the development of cognitive instruments for this purpose. Hence, engineering courses should organize their activities to achieve this learning outcome. It is thus reasonable to ask: does the current structure of engineering courses contribute to the development of the instruments of thought required to create practical solutions?

Many engineering courses are disproportionately focused on the domain of mathematics. The analysis of curricula of 10 major universities in Brazil, Canada, United States, Germany, Italy, South Korea and Singapore (Appendix A) indicates that $13 \%$ of engineering courses are purely mathematics, while $57 \%$ model phenomena based on mathematical logic; only $30 \%$ mainly apply reasoning that is not necessarily mathematical.

Calculus certainly has a great power of persuasion, it will rarely be refuted, except when someone who dominates their formal assumptions starts to challenge the application of that specific mathematical procedure to studied phenomena. When well executed, it acts as a strong argument in support of a proposed solution, even if it is based on questionable propositions. In engineering education, many discussions about physical phenomena, for example, emphasize the demonstration of formulas that describe the phenomena and only superficially analyzed the theories and concepts upon which they are founded. Thus, physics as a science is replaced by algebraic expressions that model specific aspects of phenomena, thus simplifying them. Teaching physics becomes teaching algebra operating with variables named in physics. The arguments built on algebra become fallacies, when teachers do not explain a phenomenon and only show an algebraic puzzle, using circular reasoning that has no justification beyond the presented calculation procedures.

This effort to frame the lesson in a structure similar to the cartesian scientific method aiming to reach an evidence based conclusion differs from engineering practice that deals with real open ended problems that require development of a variety of alternative solutions, from which the one considered the most suitable for the situation has to be chosen.

Returning to our main concern and recalling that corporate representatives consider that engineers need to be trained to solve industrial and commercial everyday problems and to create business opportunities by applying new ideas and discoveries into innovative processes and products (CNI, 2013) [2], begs the question: has the current way of instructing engineering courses been effective in promoting rationality?

It seems to us that something needs to be adjusted. Specifically, we need to eliminate the disconnect between professional practice that requires expertise, strategic vision and behavioral skills, in which the few calculations, when necessary, are performed with the aid of computers, versus the traditional engineering course that is structured in terms of pseudo-formal logic.

An alternative to improve the effectiveness of teaching and learning processes in engineering would be to change the way a course is conducted, making it less demonstrative and more argumentative, allowing creation of multiple solutions, encouraging critical thinking about the algorithms and the social aspects involved in a problem, and giving opportunities for students to make decisions about which is the best solutions for each specific case.

An engineering education based on argumentation potentially offers the opportunity to develop professional skills because it encourages critical thinking, stimulates reflection over the assumptions involved in the problems, structures reasoning to reach a convincing conclusion, requires decision making between several possible solutions, and culminates in the presentation of plausible justifications advocating in favor of a proposed solution. 


\section{REASONING IN ENGINEERING}

The rational being is one who uses reason to deliberate about the things in the world and reaches a consistent conclusion. The procedures of reason, or reasoning, is the application of the instrumental of thinking, accessing the collections of knowledge to establish relationships between what is known and what is observed to understand the object or to reflect, aggregate or ponder about it.

Even when conduct by an individual,, reasoning is not free from the influence of a social environment, because is affected by shared representations, memories built by community groups and knowledge accumulated in fields related to the matter. No one is alone when thinking.

Reasoning can be understood as an argumentative procedure. The organization of the premises in a sequence of plausible arguments to reach a conclusion. Reasoning is attached to arguing when we address the argument as a structured thought. Billig (2008) [6] states that "to reason is to think" considering that deliberation for a group, for an individual or for self has a dynamic that is proper to the act of thinking.

To understand the rationality required for engineering, we regard that there are two main types of reasoning, analytical and dialectical. By questioning the feasibility of formal models for each and every phenomenon, we try to show the fundamental need of common agreements about the propositions and how they have to be linked in order to reach a convincing solution.

Our day-by-day experiences are full of conflicts of opinions and meanings, and every agreement has momentary validity because at any time a controversy could be raised from somebody that sees another aspect of the topic. All content organized to defend a point of view, an argument for something, also show a counterargument to controversial opinions (BILLIG, 2008) [6]. This dynamic does not fit completely in some formal models, demanding reasoning beyond the limits of any logic, going beyond the analytical ways of organizing thought that seeks unique and irrefutably conclusive answers.

To handle such situations, we use dialectical reasoning to ponder the arguments concluding which are more and which are less compelling (Perelman, 1993) [7], and thus overcoming the ambiguity of social dynamics, in which an argumentative intervention can convince rationally some people and be assessed as unconvincing, rationally also, by others. When a group of residents of a small town considers, based on plausible reasons, that a new link road to the nearby city is a benefit to the community and that it improves the quality of life of everybody, while an environmental group claims that the benefits are small when considering the environmental impacts of the new road, we can identify different point of views, reflect on them and adhere to what is the most appropriate and/or more helpful to us.
The ways of organizing the procedures of reason were unceasingly studied throughout our history. Aristotle presented the division of argumentative procedures, those used to organize the reasoning in two basic types: the analytical demonstration, which is a logical connection in a closed system in which the correct organization of propositions results in an unequivocal conclusion, and the dialectical argumentation that is coherent rationalization based on likely ideas that follow an internal thread leading to an acceptable conclusion, which is not immune to an eventual refutation. Such reasoning, analytical and dialectic, are complementary. They cannot be overlapped or replaced by each other and must be applied individually or together according to the outlines of the object in the system of thought.

Aristotle also believed that such structures were based on syllogistic reasoning, operated by transitivity, in which the predicates of a subject are transferred to the other and transitive linking leads to the conclusion.

Formal logic is grounded in the analytical syllogism in which true propositions lead a true conclusion. This conclusion is independent of the will of men. Following the specific procedures and the proposed logical sequence, only one conclusion is possible and evident (Mazzotti, 2008) [8].

On the other hand, dialectical argument is based on the dialectical syllogism, which operates with arguments built on probable statements in order to reach credible conclusions, that are just plausible. In this case, the agreements are not necessarily based on facts, figures and places of common sense underlying the argument, and the conclusion is bolstered by more or less convincing ideas (Perelman, 1993) [7].

The starting point of argumentation is making a choice about the data that will be the basis for rationalization. As only what is deemed relevant will be used, we consider that the argumentation is a selective process. In the case of analytical reasoning, the data is interpreted and selected according to the criteria established by formal logic, which requires the univocality of elements in use, enabling everyone to understand each passage, not giving opportunity for individual interpretations.

In the dialectical reasoning, the agent chooses the data in the more convenient way for his purpose of accession. Creativity can be applied to orientate the meanings assigned to what is being exposed (Perelman and Olbrechts-Tyteca, 2000) [9]. The same fact can be described in several ways. A lesson, for example, may appear as the time limit for a teacher to present a unit of a discipline, or the opportunity to build relevant knowledge about the matter, or the connection between consolidated body of knowledge and students' personal knowledge.

A rigorous proof must go through only necessary steps; the more direct the demonstration, the more elegant it will be considered. In contrast, the argument can, between the beginning and the end which are not perfectly definable, include as many arguments as seems 
necessary, often drawing on already set agreements to increase its persuasion power.

The sequencing of arguments in logical reasoning is irrelevant, they only must be according to conventional logic. In dialectical argumentation, arguments can be organized according a reasoning structure in a way that best suits the thinking purpose about the subject.

However, when there is an agreed order about the placement of the arguments, it must be followed because breaking the expected cadence may devalue the displayed content. An order can be considered the most rational to one listener, but others could expect a distinct sequence. As the argument is a whole, their order is not just aesthetic, it acts to organize the motion reasoning cadence.

The rationality required to create solutions applicable to everyday practice integrates analytic and dialectic reasoning. Engineers must apply algorithms formally recognized within their area of operation and be able to decide among the most compelling alternatives and choose the best design solutions. The structural design criteria of a bridge must be strict, but the decision about materials to be used, supported traffic capacity, necessary maintenance routines and many other aspects of the project implementation of a bridge should take into account social, economic and environmental aspects, which must be carefully considered so as to select the optimal solution for the given the case.

Given these dynamics of thinking in engineering, it is expected that the university contributes to the development of related enabling skills, which means the courses should offer conditions to develop a rationality that integrates logic and dialectics. Are engineering courses now doing this?

In the next section, we describe how engineering classes are now organized and what types of reasoning are predominantly stimulated.

\section{TRADITIONAL EXPOSITIVE CLASSES}

Engineering offers several possibilities of educational practices to exploit perceived reality and everyday situations related to the profession. Identifying main aspects of the discourse presented by teachers of the disciplines that frame engineering courses, it is possible to analyze if the education process for undergraduates allows the effective training of the previously mentioned competencies required for professional engineers.

An exploratory research conducted by Garcia (2014) [10], aiming to understand the dynamics of engineering classes, analyzed teachers' argumentative interventions in Physics lessons that were videotaped (Appendix B), made available on Youtube and reached more than 20,000 views; this was considered an a high enough exposure level to qualify those teachers as authoritative speakers within their fields.

Youtube (http://www.youtube.com) is a valuable source of data on which classes recorded in videos made by students or by teachers are spontaneously placed on the web, for this reason we can consider these discourses and practices not influenced by observation procedure of a researcher. But among the large number of available videos, we must identify those which are representative and preferred by students, the targeted social group. This preference can reveal the influence of the teacher.

To validate a teacher as an authoritative speaker, we used the following criteria: whereas a teacher who devotes 40 hours a week to a single discipline and that time is all dedicated to teaching, has 20 classes per week. If courses are attended by 50 students, in one year the teacher will have an audience of 2,000 students. Disregarding truancy, absenteeism and other problems affecting regular attendance of classes, after 10 years working in the same discipline the teacher will have taught their discipline to 20,000 students.

With an audience of this size, this teacher can be considered an authoritative spokesperson for that discipline, because, at least in part, they contributed to the construction of knowledge of their students and helped to shape their representations about the subject.

Based on this estimation, we believe that a cutoff of 20,000 views in the collection of video lessons available on Youtube is more than adequate, recognizing the number of views is counted by clicks, and not all of these clicks correspond to complete view of classes.

The argumentative analysis begins by identifying who is speaking and what attributes qualify the speaker to the audience, including all groups that are affected by the discourse and for whom the purpose of the speech is directed.

Then, the agreements are listed to understand the foundation of all premises. Some of them based on reality, such as facts, truths and presumptions hegemonically accepted, and others based on preferable aspects, like values and notions generally shared by the students (Perelman and Olbrechts-Tyteca, 2000) [9].

Arguments can be expressed literally or be told by analogies. Therefore, it is essential to understand the predicates that are being included through metaphors and/ or metonymies, and what conceptual rearrangements are present in any dissociation of notions.

After identifying the set of assumptions and arguments, the logical structure of the discourse is examined, checking syllogisms, enthymemes and consistency of argumentative structure.

Following the above method, we can identify the elements present in various speeches so as to reveal, the main agreements and psychosocial aspects that affect the engineering education process.

The results of this specific investigation indicated that two agreements were regularly observed in Physics classes, one related to focus given to a specific content of the subject matter and other related to the manners of persuasion to get students engaged in the study of physics. 
In regards to the content, a discussion of physical phenomena was rarely emphasized and the conceptual focus was primarily on stating formulas to describe of the phenomena. Thus, Physics as a science was replaced by algebraic expressions formalizing specific aspects of the physical world and, in order to do that, simplifying the phenomena. Teaching Physics became teaching algebra in terms of variables named in Physics.

These arguments supported in algebra become fallacies because the teacher actually does not describe a phenomenon and instead present equations without clarifying they are just formalization of concepts. Equations become a kind of circular reasoning, having no justification outside the algebraic puzzle.

The analysis of teachers' speeches explains the commonplace of centrality in calculus procedures within lectures, as in the case of the teacher who introduced his first class saying "This chapter is mostly theoretical, so I'll do a lot of talking and just little or none calculations" (Youtube, 2014a) [11]. For him, it would not really be a Physics lecture when just few mathematical applications are presented.

Conceptual errors were also observed when explaining phenomena modeled by algebra, such as in the presentation of another teacher who says:

"Imagine that you will make a trip. You leave your home, go to Santos City and later return to your home. Notice you went and returned to your initial position. Your trajectory was 'your home to your final position, also your home', so the delta "S" is zero. You made a trip without moving" (Youtube, 2014b) [12].

In this case, the teacher was betrayed by the abuse of using equation or he actually does not understand the theoretical foundations of motion laws he is trying to teach.

Another important point identified in the investigated lectures, in regards to strategies for motivating students to devote themselves to the study of Physics, was that arguments are organized around the need to achieve the minimum grade to pass the course. Rarely was the importance of the subjects linked to the relevance of the knowledge acquired in the course to the reality perceived by students and everyday applications. These reasons transcend school walls and would be more effective in motivating students to dedicate their energy to the acquisition of knowledge.

Physics teachers could and should exploit more effectively experiences, demonstrations and examples of applications creating more compelling elements in their teaching strategy.

In summary, our research indicates that the discourse of Physics teachers, a disciplines emphasised in engineering education, shows two main commonalities: (1) physical phenomena should be explained by using algebraic expressions, even if it promotes degenerative simplifications of observed reality, and (2) passing the exam is a good motivator for persuading students to engage in the course, neglecting the relevance of understanding the concepts.

Such agreements are conditioned by social representations or ideologies, and indicate that, for effective training in engineering, some adjustments in the organization and conduct of lectures are necessary.

The teaching-learning process, whether in the traditional approach, which has the teacher as the "sage on the stage" serving as the only educative agent, or in contemporary visions, which put teachers as a "guide on the side" serving as a mediator who assists students in the process of acquiring knowledge and personal development, requires more than the simple demonstration of theories. It is essential that students understand the importance of developing skills and expertise offered by disciplines because they are useful in professional practice. These should be primary reasons used to persuade students to dedicate their efforts to the long process of learning.

The social field where students live stresses them about the importance of the studies, presenting their academic education as the primary goal of their lives. But for a student to devote themselves to a course, leaving aside all alternative uses of their precious time, including other disciplines, other daily duties and the necessary moments of leisure, the teacher needs to persuade them. So a rhetorical scheme suitable for success in this negotiation should be constructed by the teacher.

Moreover, a teaching model based on pre-defined problems and seeking a unique answer inhibits critical thinking and innovative solutions. Rationality is only limitedly applied when following a procedure with starting and ending points determined by the teacher. Such rigid situations will never happen in professional practice, because the dynamics of the labor starts in unstructured problems, for which different solutions are appropriate, and engineers should convince and be convinced when recommending the best of many alternative solutions for a specific case.

It is important to mention that, at the limit, when innovation opportunities are offered, an outstanding student could reach an alternative solution never envisioned by the teacher. This does not happen in traditional teaching because the whole script was already prepared by the teacher.

This organization of teaching, focused on analytical reasoning, prevents the development of complete rationality, the one required to ponder the uncertainties of everyday life, in other words, it does not allow the development of skills to deal with ambiguity, to reflect on the levels of risk, to make decisions, to understand the social environment, to respect someone else's opinions, all of which are needed for professional practice.

An alternative educational process should give the opportunity for engineering students to create solutions for open problems and defend them to their peers, thus to apply and develop their thinking skills to convince their interlocutors about the best solutions. This way of 
conducting the educational process is made possible by argumentation.

\section{ARGUMENTATION IN EDUCATION}

Argumentation is essential for education from two points of view: for students, it helps their development of critical thinking, and for teachers, it can help them organize their classes to be more appealing and optimize the achievement of proposed learning objectives.

In the specific case of engineering, extrapolating the notion of argument, we can also understand the process of solving practical problems characteristic of the field, as an argumentative construct. In fact, most engineering projects apply notions, values and agreements so as to convince all concerned parties. From the analysis of the problem, premises are established, logical reasoning is applied to identify potential solutions, then understanding of the social environment is incorporated so as to make decisions about the best solution and achieve an effective implementation.

Argumentative practices can support a learning process in various ways, such as: organizing the arguments from the body of knowledge to justify an understanding or recommendation to peers; approaching the reality in a critical and investigative way, seeking to validate the inherent ideas and concepts; or offering students opportunities to formulate affirmations and objections so as to understand, discuss and accept multiple positions (Mirza et al., 2009) [13].

The model of argumentative interventions in education believes that every class and every proposed activity, including planning, presentation, oriented interactions and their results, start by contextualizing and identifying the assumptions that affect the problem. Solution strategies can then be built based on analytical and dialectical reasoning that operates within technical, relational and social dimensions. Projects and solutions can then be presented in a schema adequate to effectively communicate recommendation and decisions in a persuasive way.

To Schwarz (2009) [14], argumentation is a tool that can be used to achieve several goals, among them, understand an object, answer a question, solve a conflict, amplify the knowledge, and communicate ideas. Learning to argue leads to the development of skills needed to organize reasoning, to justify a position, to challenge an idea, to argue and even to accept other opinions when consistent.

In an educational context, arguing is useful to solve a problem, to understand the concepts involved and to build specific knowledge on the subject, to structure the reasoning and to search for alternate solutions.

The best solution is built based on theories and techniques available in the field of study, but deal with the related values and beliefs within an argumentative context. The desire to achieve goals, knowledge of rewards when goals are reached, the understanding of difficulties to achieve the goal and beliefs about the consequences of not achieving expected results affect the decisions made in all discussions, activities and educational projects.

The development of "critical thinking" depends, at least partially, on ancient argumentative practices, that deal with the organization of content and social behavior that enables communication.

Being able to assess and establish priorities for action, determining the root causes of a problem and solving it, making better decisions, developing action plans to deliver the required results within a limited time and cost, depend on a kind of rationality that incorporates economic, strategic, social and environmental arguments.

Schwarz (2009) [14] also describes studies about the application of argumentation in teaching of Mathematics, Science and related disciplines in higher education, that indicate that the articulation of reasons and theories through argumentative interventions helps the development of the reasoning agility that is required to justify, explain, respond, and eliminate contradictions.

Students and teachers when gathering information on a topic and interacting with the views of others are exposed to a multitude of ideas what can be validated or refuted by the arguments.

Even in cases when the flaws in theory or inconsistencies of a project are exploited, it is possible to build compelling arguments based on reasons for refutation, which leads to a better understanding of what would be the right decision.

Much of traditional and current engineering education emphasizes expositive lectures, strictly delimited problems and unique answers in assessments. However, we believe that this educational environment has many features that would support a transition to productive argumentation, because there are several competing theories in any field of study, because each teacher addresses a discipline with its own point of view that it is perfectly reasonable, and because students have open minds and willingness to innovate.

\section{CONCLUSION}

Competence gaps of new engineers are not related to the technical and scientific content of their field of work. At least, these aspects are not cited by those who indicate a need for improvement in engineers' training. Even without making it clear whether the newly graduated engineers master the techniques and theories that support the profession or if these skills are not remembered because they are not of prime importance to those who analyze job performance, we consider that the behavioral, social and strategic skills are those perceived as flaws in the training process.

The current organization of engineering courses and classes have a positivist approach in which definitive evidence must be provided for every proposition about the subject in order to reach an incontestable conclusion. 
Teachers strive to frame lessons in a rigid structure similar to the cartesian scientific method, seeking convergence to an irrefutable solution. This approach diverges from the ambiguity inherent within the practice of engineering, that deals with problems that require development of various alternative solutions, from which must be selected the one deemed most appropriate for the situation.

As the essential feature of engineering is rationality to create practical solutions, requiring evaluation of feasible alternatives, careful consideration of evidence, analyzing probabilities of success and risks, assessing the adequacy of theories applied. Thus engineering education should provide the development of skills that determine this essence of an engineer's character.

Therefore, engineering schools must reconsider the exclusive use of analytical reasoning and incorporate more use of dialectical reasoning, enabling answers to discussed more realistic problems to be reached by the conviction of those involved in class, usually by consensus of teachers and students.

This way of interaction is normal in argumentation; it supports thinking critically to find fundamental concepts and organize them coherently, allowing diverse opinions in a hostile-friendly discussion towards achieving the best solution, and encourages compelling communication to achieve group consensus.

Argumentation and practical rationality are mutually dependent, each is necessary for the operation of the other. By experiencing an argumentative educational process, skills and instruments of thought supportive of practical reasoning can be developed and thus the transition to professional problem-solving activities will be natural.

\section{References}

[1] Eric Ramadi et al. 2016. Engineering graduates' skill sets in the MENA region: a gap analysis of industry expectations and satisfaction. European Journal of Engineering Education, 2016. Vol. 41, No. 1, 34-52, http://dx.doi.org/ $10.1080 / 03043797.2015 .1012707$

[2] Confederação Nacional da Indústria (CNI). Mapa Estratégico da Indústria 2013-2022. Brazil. (2016, February 01). Retrieved from http://www.portaldaindustria.com.br/cni/oque-a-cni-faz/mapa- estrategico-da-industria/2013/05/1,13421/ mapa-estrategico-da-industria-2013-2022.html>.

[3] Rosanna Martin et al. Engineering graduates' perceptions of how well they were prepared for work in industry. European Journal of Engineering Education. Vol. 30, No. 2, May 2005, $167-180$

[4] Edward Crawley, Johan Malmqvist, Sören Östlund, and Doris Brodeur, Rethinking Engineering Education: The CDIO Approach. New York, NY: Springer, 2010 (2nd ed.), 300 pp. \{ISBN: 978-1441-94260-9\}
[5] Antoine Picon. Engineers and Engineering History: Problems and Perspectives. History and Technology. Vol. 20, No. 4, 421-43, 2004.

[6] Michael Billig. Argumentando e pensando: uma abordagem retórica à psicologia social (Vera Lúcia Mello Joscelyne, Translation to Portuguese). Petrópolis, Rio de Janeiro: Editora Vozes, 2008. \{ISBN 978-85-326-3619-5\}

[7] Chaïm Perelman. O império retórico: retórica e argumentação. (Fernando Trindade and Rei Alexandre Grácio, Translation to Portuguese). Porto: Edições Asa, 1993. \{ISBN 972-41-1128-8\}

[8] Tarso B. Mazzotti. The Rhetoric Turn. In Michael Taylor, Helmut Schreier and Paulo Ghiraldelli Jr. (Eds.). Pragmatism, Education, and Children: International Philosophical Perspectives. Amsterdam/New York, NY: Rodopi, 2008, p. 203-224. $\{978-90-4202342-0\}$

[9] Chaïm Perelman and Lucie Olbrechts-Tyteca. Tratado da Argumentação: a Nova Retórica (Maria Ermantina Galvão, Translation to Portuguese). São Paulo: Martins Fontes, 2000. \{ISBN 85-336-0473-4\}

[10] Adriano J. Garcia, "Representações sociais do ensino de engenharia: pelas metáforas que coordenam os discursos", in 12a. Conferência Internacional sobre Representações Sociais, CIRS2014 (São Paulo, Brazil, 20-23 July 2014). pp.1091-1098. \{ISBN: 978-85-60876-01-3\}

[11] Youtube. Aula do Curso Regular de Graduação Física Geral I. Instituto de Física Gleb Wataghin da Universidade Estadual de Campinas. Presented by Professor Luiz Marco Brescansin. (2014, March 30). Retrieved from http://youtu.be/ bJuoKyIG13A.

[12] Youtube. Física - Cinemática - Aula 1. Portal Stoodi. Presented by Professor Wanys Rocha. (2014, March 30). Retrieved from http://youtu.be/WUUdb-ptaI0.

[13] Nathalie M. Mirza et al., Psychosocial Processes in Argumentation. In Nathalie M. Mirza and Anne-Nelly PerretClermont (eds.), Argumentation and Education: Theorectical Foundations and Practices (pp. 67-90), New York, NY: Springer, 2009. \{ISBN 978-0-387-98124-6\}

[14] Baruch B. Schwarz, Argumentation and Learning. In Nathalie M. Mirza and Anne-Nelly Perret-Clermont (eds.), Argumentation and Education: Theorectical Foundations and Practices (pp. 91-126), New York, NY: Springer, 2009. \{ISBN 978-0-387-98124-6\}

\section{APPENDIX A: MECHANICAL ENGINEERING CURRICULA ANALYSIS}

The analysis of curricula of 10 major universities listed below indicates that $13 \%$ of the disciplines of engineering courses are purely mathematics (such as Calculus, Linear Algebra and Probabilities), 57\% are disciplines that model phenomena on mathematical logic (such as Physics, Thermodynamics, Computational Methods and Economics) and 30\% mainly apply reasonings that are 
not necessarily mathematical (such as Chemistry, Engineering Project, Production Management and Environmental Studies).

\begin{tabular}{|l|c|c|l|}
\hline University / Course & $\%$ Math & $\begin{array}{l}\% \text { Math } \\
\text { Modeled }\end{array}$ & Source \\
\hline $\begin{array}{l}\text { South Korea KAIST / Mechanical } \\
\text { Engineering }\end{array}$ & $2 \%$ & $68 \%$ & $\begin{array}{l}\text { KAIST Department of Mechanical } \\
\text { Engineering - Curriculum }\end{array}$ \\
\hline $\begin{array}{l}\text { Singapore NUS Bachelor of } \\
\text { Engineering / Mechanical } \\
\text { Engineering }\end{array}$ & $12 \%$ & $52 \%$ & $\begin{array}{l}\text { Sample semestral schedule for ME } \\
\text { Students - Registrar's Office }\end{array}$ \\
\hline $\begin{array}{l}\text { Michigan State University (USA) - } \\
\text { College of Engineering / Mechanical } \\
\text { Engineering }\end{array}$ & $13 \%$ & $60 \%$ & $\begin{array}{l}\text { Mechanical Engineering Sample } \\
\text { Program }\end{array}$ \\
\hline $\begin{array}{l}\text { Technische Universität München } \\
\text { (Germany) / Mechanical Engineering }\end{array}$ & $14 \%$ & $78 \%$ & $\begin{array}{l}\text { Mechanical Engineering } \\
\text { Annual Report 2015 }\end{array}$ \\
\hline $\begin{array}{l}\text { Politecnico di Milano (Italy) / } \\
\text { Mechanical Engineering }\end{array}$ & $17 \%$ & $58 \%$ & $\begin{array}{l}\text { Manifesti degli Studi - Degree } \\
\text { Program }\end{array}$ \\
\hline $\begin{array}{l}\text { Faculty of Applied Science and } \\
\text { Engineering - University of Toronto } \\
\text { (Canada) / Mechanical Engineering }\end{array}$ & $17 \%$ & $46 \%$ & $\begin{array}{l}\text { Current Engineering } \\
\text { Undergraduates Website }\end{array}$ \\
\hline $\begin{array}{l}\text { Faculty of Engineering - McGill } \\
\text { University (Canada) / Mechanical } \\
\text { Engineering }\end{array}$ & $16 \%$ & $52 \%$ & $\begin{array}{l}\text { Undergraduate Student Handbook } \\
2015-2016\end{array}$ \\
\hline $\begin{array}{l}\text { Universidade Estácio de Sá (Brazil)/ } \\
\text { Mechanical Engineering }\end{array}$ & $16 \%$ & $46 \%$ & $\begin{array}{l}\text { Matriz Curricular e Carga Horária } \\
\text { do Curso (Curriculum and } \\
\text { schedule) }\end{array}$ \\
\hline $\begin{array}{l}\text { Centro Universitário da FEI (Brazil) / } \\
\text { Mechanical Engineering }\end{array}$ & $9 \%$ & $64 \%$ & Plano Pedagógico (Teaching Plan) \\
\hline $\begin{array}{l}\text { Universidade Federal de Santa } \\
\text { Catarina (Brazil) / Mechanical } \\
\text { Engineering }\end{array}$ & $18 \%$ & $49 \%$ & Currículo do Curso (Curriculum) \\
\hline
\end{tabular}

\section{APPENDIX B: PHYSICS LECTURES VIDEOS}

List of Physics lectures videos collected in Youtube which had the teachers' argumentative interventions analyzed.

\begin{tabular}{|c|l|c|l|}
\hline Id & \multicolumn{1}{|c|}{ Title } & $\begin{array}{c}\text { Views (till } \\
\text { 2014-03-30) }\end{array}$ & \multicolumn{1}{c|}{ Link } \\
\hline v.1 & $\begin{array}{l}\text { Cursos Unicamp: Física Geral 1/ } \\
\text { aula 1 }\end{array}$ & 102.569 & $\underline{\text { http://youtu.be/bJuoKyIG13A }}$ \\
\hline v.2 & $\begin{array}{l}\text { Física - aula - Movimento harmônico } \\
\text { Simples MHS - Oscilações }\end{array}$ & 55.809 & http://youtu.be/uYE-zZVUBTg \\
\hline v.3 & $\begin{array}{l}\text { Física Geral III - Aula 1 - Carga } \\
\text { Elétrica - Parte 1 }\end{array}$ & 53.867 & $\underline{\text { http://youtu.be/lfNvbJbYxFQ }}$ \\
\hline v.4 & FISICA-CINEMáTICA (.AULA 1) & 53.344 & http://youtu.be/WUUdb-ptaI0 \\
\hline v.5 & $\begin{array}{l}\text { Cursos Unicamp - Física Geral II - } \\
\text { Calor e 1 }{ }^{\mathrm{a}} \text { Lei da Termodinâmica }\end{array}$ & 41.128 & $\underline{\text { http://youtu.be/LVJyxS-sO0w }}$ \\
\hline v.6 & $\begin{array}{l}\text { Hidrodinâmica - Equação de } \\
\text { Bernoulli }\end{array}$ & 34.897 & http://youtu.be/UiG6jgGoyug \\
\hline v.7 & $\begin{array}{l}\text { Resistencia dos materiais - Prof } \\
\text { Elivaldo }\end{array}$ & 20.103 & http://youtu.be/LOmVjrIZ0Uk \\
\hline
\end{tabular}

